ASTHMA

\title{
Case-control study of severe life threatening asthma (SLTA) in a developing community
}

\author{
L van der Merwe, A de Klerk, M Kidd, P G Bardin, E M van Schalkwyk
}

Thorax 2006;61:756-760. doi: 10.1136/thx.2005.052308

See end of article for authors' affiliations .....................

Correspondence to: Professor P G Bardin, Monash Medical Centre/ University, 246 Clayton Road, Clayton 3168, Melbourne, Australia; p.bardin@southernhealth org.au

Received 8 October 2005 Accepted 21 March 2006
Background: Distinct risk factors for asthma death have not been identified in developing communities. This study was conducted to distinguish risk factors for severe life threatening asthma (SLTA), a proxy for asthma death, in a developing country.

Methods: A case-control study was performed at a University Hospital serving developing communities in the Western Cape Province, South Africa, over the period October 1997 to April 2000. Thirty consecutive patients with SLTA admitted to the intensive care unit (ICU) were compared with 60 chronic asthmatic patients, without a history of SLTA, who had attended the hospital outpatient respiratory clinic over the same period.

Results: The risk of SLTA in comparison with controls increased with female sex (odds ratio (OR) 3.3, 95\% $\mathrm{Cl} 1.2$ to $9.6, \mathrm{p}=0.02$ ), rural residence (OR 8.1,95\% $\mathrm{Cl} 2.6$ to $25.3, \mathrm{p}=0.0005$ ), and absence of a formal income (OR 5.7, 95\% Cl 2 to 16.6, $p=0.002$ ). Cases were more likely to have had more than one hospital admission in the previous year (OR 8,95\% Cl 2.5 to 25.2, $p=0.0009$ ) and more than one emergency room visit in the previous year (OR 4.4,95\% $\mathrm{Cl} 1.19$ to $16.4, \mathrm{p}=0.04$ ). Patients with SLTA were less likely to use inhaled corticosteroids (OR 5.6,95\% $\mathrm{Cl} 1.9$ to $16.5, \mathrm{p}=0.003$ ) and more likely to use inhaled fenoterol (OR 6, 95\% Cl 2.2 to 16.2, $p=0.0004)$. Patients with SLTA also had lower mean (SE) forced expiratory volume in 1 second $\left(\mathrm{FEV}_{1}\right)$ measurements $(66.9(9.5) \%$ predicted $v 82.5(4.0) \%$ predicted; $p=0.03$ ) and lower $\mathrm{FEV}_{1} / \mathrm{FVC}$ ratios $(60.7$ (4.1)\% predicted $v 69.6$ (1.9)\% predicted; $\mathrm{p}=0.05)$ documented before the episode of SLTA.

Conclusions: Risk factors for SLTA that are mainly analogous to those distinguished in other environments have been identified in a geographical area characterised by a third world socioeconomic context. Rural residence and poverty may increase the risk of SLTA.
$\mathrm{F}$ actors related to asthma mortality are difficult to study because only small numbers of asthmatics ultimately have fatal disease. The use of severe life threatening asthma (SLTA) as a proxy for fatal asthma ${ }^{12}$ has permitted greater numbers of patients at risk of asthma death to be evaluated, although SLTA itself is an important outcome worthy of investigation. Appropriate case-control studies have added significantly to our current understanding of risk factors for SLTA exacerbations and have identified key factors including limited healthcare utilisation, insufficient antiinflammatory therapy, and decreased lung function. ${ }^{13-7}$ Other factors predisposing to fatal asthma comprise lack of access to health care, poor quality and fragmented asthma management, lack of treatment adherence, absence of inhaled corticosteroid treatment, and failure to appreciate warning symptoms. ${ }^{148-12}$ Our understanding of asthmatics at risk has also been enhanced by mortality trend analyses that have characterised asthma deaths according to age, sex, race, social class, geographical location, and time of event. ${ }^{13-17}$ Most studies were conducted in westernised countries with relatively sophisticated medical, economic and social infrastructures and, to date, it is not clear whether risk factors identified in these countries have the same relevance in developing regions. It is possible that other unique factors may play a role in countries that are at an earlier stage of socioeconomic development.

There appears to be a disproportionately high morbidity and mortality from asthma in the Western Cape Province of South Africa. ${ }^{15}$ The number of deaths from asthma in this region exceeds that in developed countries ${ }^{13}{ }^{18}$ and in many developing countries. ${ }^{14} 19$ Although asthma is common in Africa, there are few data on risk factors for SLTA and little published information pertaining to developing regions in subSaharan Africa. Our recent hospital based study in Cape Town compared patients with SLTA to asthmatics with acute severe asthma in an emergency room and found significant associations with previous admissions to an intensive care unit (ICU) and underuse of $\beta$ agonists prior to admission. ${ }^{9}$ However, the controls chosen for comparison with SLTA might have been similar in key respects to the SLTA group and unique risk factors could have been overlooked, a dilemma emphasised in an analogous Australian study. ${ }^{20}$

Distinctive risk factors for SLTA in developing countries have not been elucidated. We investigated risk factors in this environment using a case-control design.

\section{METHODS}

\section{Study design and setting}

The study was performed at Tygerberg Academic Hospital, a 1200 bed tertiary care hospital associated with the University of Stellenbosch, Cape Town, South Africa, over the period October 1997 to April 2000. A case-control design was chosen because it provides an efficient method for studying rare disease outcomes. ${ }^{21}$ The hospital is one of two tertiary care hospitals in the Western Cape Province and serves a geographical area that includes a rural component (approximately 50\%). Patients in both rural and metropolitan areas have free access to regional clinics and hospitals with emergency departments. However, patients who may require specialised care or ICU admission are referred to the tertiary

Abbreviations: $\mathrm{FEV}_{1}$, forced expiratory volume in 1 second; FVC, forced vital capacity; ICU, intensive care unit; SLTA, severe life threatening asthma 
care hospital. The Combined Ethics Committee of the University of Stellenbosch and Tygerberg Academic Hospital approved the study.

For the purposes of this study, SLTA was defined as admission to an ICU for acute severe asthma following physician review in the emergency room. All cases admitted to an ICU between October 1997 and April 2000 with physician diagnosed respiratory failure due to an exacerbation of asthma were included. ${ }^{1}$ Criteria for admission included: arterial carbon dioxide tension $\left(\mathrm{PaCO}_{2}\right)>6.0 \mathrm{kPa}$ $(n=6)$, impaired consciousness $(n=3)$, respiratory arrest $(n=12)$, requirement for mechanical ventilation $(n=4)$, and significant hypoxia (transcutaneous oxygen saturation $<92 \%)$ with severe airway obstruction $(n=5)$. The criteria for admission were unchanged over the duration of study. One case also had a diagnosis of "COPD" noted in addition to asthma. To minimise misclassification of chronic obstructive airway disease (COPD) as asthma, patients older than 45 years were excluded; patients younger than 13 years old were not admitted to the "adult" ICU and were also excluded.

Controls were selected from asthmatic patients attending the outpatient Respiratory Clinic at the same hospital over the same period. The clinic is a specialist assessment facility established to optimise management of moderate to severe asthmatics from both the metropolitan and rural geographical areas. Sixty subjects (every 30th patient of 1570 patients according to the clinic attendance registers) aged 13-45 years were selected. Any subjects with a history of an asthma related admission to an ICU $(n=1)$ were excluded from the control group and replaced by the next patient on the attendance register. No other matching was undertaken as it was considered that features traditionally matched such as age and sex may also be risk factors.

\section{Patient data}

Information was obtained from patients' case records and possible risk factors such as age, sex, population group, area of residence, occupation, and income were recorded. Areas of residence were categorised as urban (within the metropolitan area as defined by hospital protocols) or rural (farm or rural town outside metropolitan area). Health indicators noted included concomitant allergic disease (hay fever, eczema, allergic conjunctivitis), smoking habit, a history of previous pulmonary tuberculosis, and number of hospital and emergency room admissions in the previous year. A psychobehavioural disorder was noted if any history of a mood disorder, psychotic episode, neurosis, or substance abuse had been documented.

Asthma treatment before the SLTA episode was investigated using all available source data in the patient record including copies of pharmacy records and prescriptions. The use of inhaled corticosteroid, type of inhaled $\beta$ agonist, use of theophylline, and use of regular oral corticosteroids in the previous 12 months were noted. Documented evidence of poor adherence with prescribed medication was noted, and this information was combined with documentation from clinic records confirming two or more missed clinic outpatient appointments in the previous 12 months. The absence of any entry in this regard was construed as "good compliance" unless records were inadequate for assessment in the opinion of the investigator.

Pulmonary function measurements conducted in the 12 months before the episode of SLTA were available in patients with SLTA who had been regularly reviewed in the hospital clinic $(n=12)$. All pulmonary function measurements were performed to conform to standard ATS criteria, ${ }^{22}$ and comparisons were made with measurements from control subjects obtained as part of their clinic review $(\mathrm{n}=60)$.

\section{Statistical analysis}

Sample size was based on data reported by case-control studies of SLTA in adults that demonstrated adequate statistical power to detect significant differences in key risk factors. ${ }^{5}$ Results of descriptive statistics are given as mean (SE) for continuous variables and percentages for categorical variables. The demographic and physiological characteristics of the SLTA group were compared with the control group using the Student's $t$ test (continuous variables) and the $\chi^{2}$ test (categorical variables). Univariate analyses were performed to examine predictive variables. Odds ratios (OR) with 95\% confidence intervals (CI) were calculated for categorical variables. To investigate the combined effect of various variables on the case/control variable, a best subsets discriminant analysis was performed but the final sample was too small to give meaningful results due to missing values in some of the variables. A two sided value of $\mathrm{p}<0.05$ was accepted as statistically significant.

\section{RESULTS}

\section{Patients and demographic characteristics}

During the study period 30 patients were identified who had been admitted to the ICU as a result of SLTA (table 1). There were four deaths in the group (13\%). Eight patients had been admitted to the ICU on previous occasions (27\%); two patients each had a history of four, three, two and one previous ICU admissions, respectively.

Baseline demographic characteristics are shown in table 1. There was an association between SLTA and female sex (SLTA $83.3 \% v$ controls 60\%; $\mathrm{p}=0.02$ ) and rural residence $(36.7 \% \vee 6.7 \% ; p=0.0005)$. Lack of formal employment was also associated with SLTA $(39.3 \% v 10.2 \% ; \mathrm{p}=0.002)$.

\section{Medical history}

Patient medical information and asthma history are presented in table 2. SLTA was associated with a significantly higher mean number of hospital admissions in the previous year than controls $(1.48 \vee 0.52 ; \mathrm{p}=0.0005)$, and with a history of more than one hospital admission in the previous year $(42.9 \% \quad v 8.6 \% ; \mathrm{p}=0.0009)$. The mean number of

\begin{tabular}{|c|c|c|c|c|}
\hline & $\begin{array}{l}\text { SLTA } \\
(\mathrm{N}=30)\end{array}$ & $\begin{array}{l}\text { Controls } \\
(\mathrm{N})=60\end{array}$ & $p$ value & OR $(95 \% \mathrm{Cl})$ \\
\hline Mean (SE) age (years) & $31(1.7)$ & $30.8(1.1)$ & 0.6 & \\
\hline Sex (\% female) & 83.3 & 60 & 0.02 & $3.3(1.2$ to 9.6$)$ \\
\hline Domicile (\% rural) & 36.7 & 6.7 & 0.0005 & 8.1 (2.6 to 25.3 ) \\
\hline \multicolumn{5}{|l|}{ Income } \\
\hline $\begin{array}{l}\text { Mean (SE) income per } \\
\text { month (rand) }\end{array}$ & $878(174)$ & $1297(124)$ & 0.06 & $5.7(2$ to 16.6$)$ \\
\hline No formal income (\%) & $39.3(11 / 28)$ & $10.2(6 / 59)$ & 0.002 & \\
\hline
\end{tabular}

Where data are not available for the complete group, numbers are given in parentheses. 
Table 2 Medical and allergic factors in study subjects

\begin{tabular}{|c|c|c|c|c|}
\hline & $\begin{array}{l}\text { SLTA } \\
(\mathrm{N}=30)\end{array}$ & $\begin{array}{l}\text { Controls } \\
(\mathrm{N}=60)\end{array}$ & $p$ value & OR $(95 \% \mathrm{Cl})$ \\
\hline Hay fever/rhinitis (\%) & $37.5(9 / 24)$ & 45 & 0.53 & $1.4(0.5$ to 3.6$)$ \\
\hline Atopic dermatitis (\%) & $29(7 / 24)$ & $25(14 / 56)$ & 0.69 & $1.2(0.4$ to 3.6$)$ \\
\hline \multicolumn{5}{|l|}{ Smoking } \\
\hline Mean (SE) pack-years & $13.2(2.4)$ & $8.5(1.5)$ & 0.13 & \\
\hline Mean (SE) hospital admissions & $1.48(0.2)$ & $0.52(0.14)$ & 0.0005 & \\
\hline$>1$ hospital admission (\%) & $42.9(9 / 21)$ & $8.6(5 / 58)$ & 0.0009 & 8 (2.5 to 25.2$)$ \\
\hline Mean (SE) ER visits* ${ }^{\star}$ & $1.29(0.27)$ & $0.57(0.15)$ & 0.02 & $4.4(1.2$ to 16.4$)$ \\
\hline$>1$ ER visit (\%) & $29(5 / 17)$ & $8.6(5 / 58)$ & 0.04 & \\
\hline History of previous PTB (\%) & $14.3(3 / 21)$ & $28.8(17 / 59)$ & 0.17 & $2.4(0.7$ to 9.1$)$ \\
\hline Psycho-behavioural disorder (\%) & $17(5 / 29)$ & 5 & 0.07 & $4(1$ to 16.5$)$ \\
\hline
\end{tabular}

emergency room visits differed between the cases and controls $(p=0.02)$, and SLTA was associated with having had more than one emergency room visit in the previous year $(29 \% v 8.6 \% ; p=0.04)$. Allergic disease affecting other organ systems (hay fever, eczema, allergic conjunctivitis), smoking, and a history of pulmonary tuberculosis were not associated with an increased risk of SLTA. There tended to be more patients with psycho-behavioural disorders in the SLTA group $(17 \% \vee 5 \% ; \mathrm{p}=0.07)$.

\section{Treatment}

Patient treatment with asthma medications is shown in table 3. The SLTA group was more often not on inhaled corticosteroid treatment $(43.3 \%)$ than controls $(12.1 \%$; $\mathrm{p}=0.003)$. Inhaled fenoterol use $(200 \mu \mathrm{g}$ metered dose inhaler) was also significantly associated with SLTA $(p=0.0004)$, but use of fenoterol was not linked to area of residence because similar numbers of rural and urban subjects were using fenoterol (not shown). All but one patient in the SLTA group were either using fenoterol or salbutamol, and only one patient in the SLTA group was using an inhaled anticholinergic agent. Reliable information about prescribed doses of $\beta$ agonist and inhaled corticosteroid medication was not available for comparison. There was a trend suggesting reduced adherence with treatment in the SLTA group (73\% v 51.7\%; $\mathrm{p}=0.05)$.

\section{Pulmonary function measurements}

It was possible to assess pulmonary function measurements performed before the episode of SLTA in a subgroup of patients. Data are shown in fig 1. The SLTA group had more severe airway obstruction as judged by reduced FEV $_{1}$ (SLTA $66.9(9.5) \%$ predicted $v$ control $82.5(4.0) \% ; \mathrm{p}=0.03)$ and $\mathrm{FEV}_{\mathrm{l}} / \mathrm{FVC}$ ratio $(60.7(4.1) \%$ v $69.6(1.9) \% ; \mathrm{p}=0.05)$.

\section{DISCUSSION}

Developing countries are faced with unique social and healthcare problems that may need a modified approach to ensure realistic efforts are made to prevent asthma deaths. We performed a case-control study to assess risk factors for SLTA in a community experiencing socioeconomic growth and development. Our results show that risk factors in this setting are comparable in most respects to those identified in countries with a mature health care and social infrastructure, ${ }^{13-7} 10-12$ although a number of factors highlighted in the study could be viewed as being more distinctive of a developing environment.

Although risk factors for asthma death have been identified in the US, Canada, UK, Europe, Australia, New Zealand and other countries, little information is available in developing countries such as South Africa. We recently conducted a prospective hospital based study comparing demographic and disease features of SLTA with characteristics of patients admitted to an emergency room with nonlife-threatening acute severe asthma. ${ }^{9}$ The study identified known risk factors such as previous ICU admission, but failed to differentiate other characteristics that may distinguish patients at risk of fatal asthma. This may have been because patients with acute asthma admitted to the emergency room include subjects who share disease characteristics with those at risk of SLTA. ${ }^{20}$ By nature of their design, some previous studies may also have included subjects with a propensity for SLTA in their control group. ${ }^{135}$ To overcome confounding by this aspect, we studied cases of SLTA and selected nonhospitalised asthmatic outpatients from the same geographical area for comparison, having verified that they did not have a previous episode of SLTA.

The study showed several key differences between patients with SLTA and controls. Subjects from a rural area and without a formal income were more at risk of SLTA, a finding

Table 3 Treatment with asthma medications in study patients

\begin{tabular}{|c|c|c|c|c|}
\hline & $\begin{array}{l}\text { SLTA } \\
(\mathrm{N}=30)\end{array}$ & $\begin{array}{l}\text { Controls } \\
(\mathrm{N}=60)\end{array}$ & $p$ value & OR $(95 \% \mathrm{Cl})$ \\
\hline No use of inhaled corticosteroid (\%) & $43.3(10 / 23)$ & $12.1(7 / 58)$ & 0.003 & 5.6 (1.9 to 16.5$)$ \\
\hline $\begin{array}{l}\text { Regular oral corticosteroid (\%) } \\
\beta \text { agonists }(\%)\end{array}$ & $16(4 / 25)$ & $7(4 / 57)$ & 0.22 & $2.5(0.6$ to 10.6$)$ \\
\hline Inhaled fenoterol* & $68(17 / 25)$ & $28.8(17 / 59)$ & 0.0004 & $6(2.2$ to 16.2$)$ \\
\hline Theophylline (\%) & $76(19 / 25)$ & 56.7 & 0.09 & $1.8(0.7$ to 4.9$)$ \\
\hline Poor adherence with treatment (\%) & $73(22 / 30)$ & $51.7(30 / 58)$ & 0.05 & $2.6(1$ to 6.6$)$ \\
\hline
\end{tabular}

Where data are not available for the complete group, numbers are given in parentheses.

*Subjects not on fenoterol were on salbutamol except for one patient in the SLTA group who was using inhaled anticholinergic medication. 


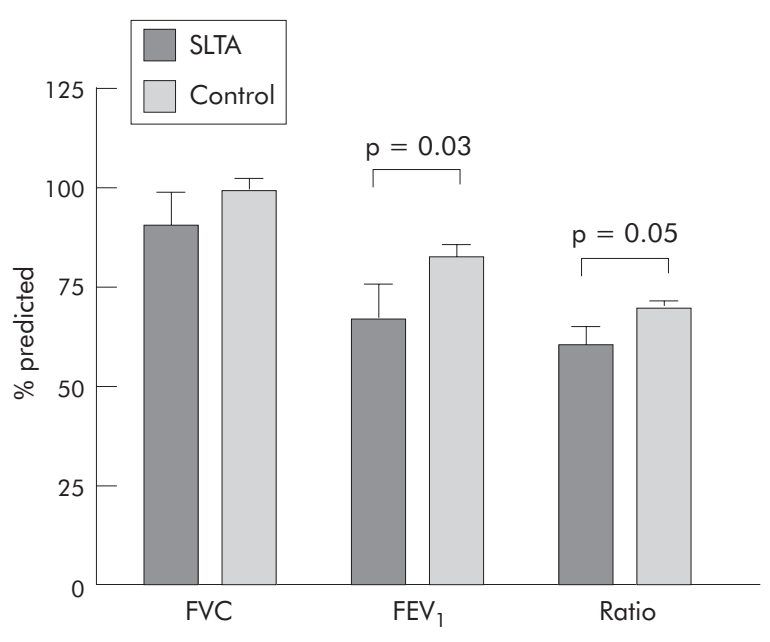

Figure 1 Measurement of pulmonary function in patients with severe life threatening asthma (SLTA) and controls.

previously documented in the UK and Australia. ${ }^{11}{ }^{16}{ }^{17}$ Living in a rural area may limit access to specialised care that, in turn, could lead to suboptimal asthma management, particularly in severe asthma. Our data also confirmed an association between SLTA and low economic standing as reflected by a lack of formal income. A link between rural residence and meagre socioeconomic circumstances may also exist but was not observed. We could not find any association between SLTA and atopic disorders as noted in previous studies, ${ }^{10}$ but a possible connection with psycho-behavioral disorders was noted. Interestingly, there was a non-significant twofold difference in pulmonary tuberculosis between the case and control groups. However, the finding should be interpreted with caution because it was based solely on history and not verified by other methods.

The study again showed the well documented link between SLTA and previous admissions to hospital for asthma exacerbations. ${ }^{135}$ The SLTA group had a significantly higher mean number of hospital admissions in the previous year, and having had more than one hospital admission increased the risk for SLTA eightfold. It was also noteworthy that $27 \%$ of the patients with SLTA had one or more previous ICU admissions. These findings are of particular importance in developing countries where access for severely ill patients to an ICU is often limited. Patients who fall in this group should be identified and prioritised to ensure early referral to an appropriate medical facility.

It is likely that lack of treatment with inhaled corticosteroids represents one of the cardinal risk factors for SLTA. Ernst and co-workers ${ }^{23}$ have shown that subjects who had been dispensed one or more beclometasone inhalers per month for a year had a significantly lower risk of fatal asthma. The results in a developing environment confirm that the risk of SLTA was significantly increased in those asthmatics not treated with inhaled corticosteroid. It was not possible to ascertain the reasons for the absence of treatment with inhaled corticosteroid, but limited access to health care, inadequate provision of inhaled corticosteroid, and poor patient adherence may have contributed. The results identify an important area of asthma management that may be lacking in developing countries, and suggest that treatment with inhaled corticosteroid denotes an important opportunity for countries with limited financial resources to reduce the costs of ICU treatments as well as the risk of SLTA and asthma fatalities.

The use of inhaled fenoterol has been proposed as an independent risk factor for asthma death, ${ }^{67}$ although the association may be confounded by asthma severity. ${ }^{24}$ In this study a significantly greater proportion of the SLTA group was using inhaled fenoterol, increasing the odds for SLTA fivefold. These findings provide further support for the notion that use of fenoterol is linked to asthma death. We could not exclude confounding of an association by asthma severity. Asthma severity may be linked to the use of oral corticosteroid or theophylline medications, but we found no association between SLTA and the use of these medications. Moreover, similar proportions of patients from rural and urban areas used fenoterol and salbutamol, implying that the results were not caused by different patterns of $\beta$ agonist prescription in rural areas.

Routine pulmonary function measurements before the SLTA episode are of interest but have not been reported in many studies. In this study reliable measurements were available in approximately $40 \%$ of the SLTA group. Analysis indicated that these patients had lower predicted $\mathrm{FEV}_{1}$ and $\mathrm{FEV}_{\mathrm{l}} / \mathrm{FVC}$ ratios than controls, suggesting greater levels of airway obstruction. It implies that a more severe asthma phenotype may have been present or that control of asthma was not optimised in the SLTA group. Better asthma control might have prevented SLTA in some cases, a notion that seems feasible in the light of recent evidence that optimal control of chronic asthma can reduce exacerbations as well as hospital admissions. ${ }^{25}$

The study has a number of shortcomings. Firstly, it may have been underpowered for uncommon risk variables, so limiting some comparisons. However, the research design used and the number of subjects enrolled were adequate to permit detection of risk factors that are analogous to risk variables noted in studies of comparable design and conducted in developed countries; in addition, the current study identified variables that appear to characterise a developing region. Referral bias could occur using our study design, especially with regard to the selection of case and control groups and the rural/urban components of our study. Sub-analyses did not suggest this to be a significant factor in the study. Finally, independent risk factors could not be assessed using multivariate techniques because subject numbers were too small for robust analysis.

In conclusion, we have identified risk factors for SLTA in the context of a developing country. Our findings are generally in concordance with results of studies from developed countries such as the USA, Canada, Australia, UK and New Zealand, and confirm the multifactorial nature of risk factors for SLTA. It is noteworthy that SLTA is universally found, but factors predicting SLTA depend on the patient population under study. It suggests that an additional "universal" component (for example, viral origins of exacerbations or patient innate immune responses to infections) may contribute to severity. ${ }^{26}$ Finally, this study details potentially reversible risk factors specific to this geographical region and indicates areas that should be targeted in order to reduce the risk of asthma fatality.

\section{ACKNOWLEDGEMENTS}

The authors thank BW van de Wal for reviewing the manuscript and E Wanza and M Koopman for assistance with data collection and entry.

\section{Authors' affiliations}

L van der Merwe, A de Klerk, P G Bardin, E M van Schalkwyk, Lung Unit, Department of Internal Medicine, Tygerberg Hospital and

University of Stellenbosch, Cape Town, South Africa

M Kidd, Centre for Statistical Consultation, University of Stellenbosch, Cape Town, South Africa

P G Bardin, Department of Respiratory and Sleep Medicine, Monash Medical Centre and University, Melbourne, Australia 
Funding for the study was provided by The University of Stellenbosch, School of Medicine, Cape Town, RSA and Monash University, Melbourne, Australia.

Competing interests: none declared

\section{REFERENCES}

1 Kolbe J, Fergusson W, Vamos $M$, et al. Case-control study of severe life threatening asthma (SLTA) in adults: demographics, health care, and management of the acute attack. Thorax 2000;55:1007-15.

2 Beasley R, Pearce N, Crane J. Use of near fatal asthma for investigating asthma deaths. Thorax 1993;48:1093-4.

3 Rea HH, Scragg R, Jackson R, Beaglehole R, Fenwick J, Sutherland DC. A case-control study of deaths from asthma. Thorax 1986;41:833-9.

4 Tough S, Hessel PA, Ruff M, et al. Features that distinguish those who die from asthma from community controls with asthma. J Asthma 1998;35:657-65.

5 Turner MO, Noertjojo K, Vedal S, et al. Risk factors for near-fatal asthma. A case-control study in hospitalized patients with asthma. Am J Respir Crit Care Med 1998;157:1804-9.

6 Pearce N, Crane J, Burgess C, et al. Beta-agonists and death from asthma. N Engl J Med 1992;327:355-7.

7 Spitzer WO, Suissa S, Ernst $P$, et al. The use of beta-agonists and the risk of death and near death from asthma. N Engl J Med 1992;326:501-6.

8 Kallenbach JM, Frankel AH, Lapinsky SE, et al. Determinants of near fatality in acute severe asthma. Am J Med 1993;95:265-72.

9 de Klerk A, van Schalkwyk E, Williams Z, et al. Risk factors for near-fatal asthma: a case-control study in a Western Cape teaching hospital. S Afr Med J 2002;92:140-4.

10 Abramson MJ, Bailey MJ, Couper FJ, et al. Are asthma medications and management related to deaths from asthma? Am J Respir Crit Care Med $2001 ; 163: 12-8$.

11 Tong S, Drake P. Hospital admission and mortality differentials of asthma between urban and rural populations in New South Wales. Aust J Rural Health 1999;7:18-22.
12 Horn C, Clark TH, Cochrane G. Compliance with inhaled therapy and morbidity from asthma. Respir Med 1990;84:67-70.

13 Campbell MJ, Cogman GR, Holgate ST, et al. Age specific trends in asthma mortality in England and Wales, 1983-95: results of an observational study. BMJ 1997;314:1439-41.

$14 \mathrm{Ng}$ TP, Tan WC. Temporal trends and ethnic variations in asthma mortality in Singapore, 1976-1995. Thorax 1999;54:990-4.

15 Zar HJ, Stickells D, Toerien A, et al. Changes in fatal and near-fatal asthma in an urban area of South Africa from 1980-1997. Eur Respir J $2001 ; 18: 33-7$

16 Higgins BG, Britton JR. Geographical and social class effects on asthma mortality in England and Wales. Respir Med 1995;89:341-6.

17 Jones AP, Bentham G. Health service accessibility and deaths from asthma in 401 local authority districts in England and Wales, 1988-92. Thorax 1997:52:218-22.

18 Sly RM. Decreases in asthma mortality in the United States. Ann Allergy Asthma Immunol 2000;85:121-7.

19 Neffen H, Baena-Cagnani C, Mslka S, et al. Asthma Mortality in Latin America. J Investig Allergol Clin Immunol 1997;7:249-53.

20 Campbell DA, McLennan G, Coates JR, et al. A comparison of asthma deaths and near-fatal asthma attacks in South Australia. Eur Respir J 1994;7:490-7.

21 Rothman K. Types of epidemiology studies. In: Rothman K, Greenland S, eds. Modern epidemiology. Boston: Little Brown, 1986:51-76.

22 American Thoracic Society. Standardization of spirometry. 1994 update. Am J Respir Crit CareMed 1995; 152:1 107-36.

23 Ernst $P$, Spitzer W, Suissa S, et al. Risk of fatal and near-fatal asthma in relation to inhaled corticosteriod use. JAMA 1992;268:3462-4.

24 Rea HH, Garrett JE, Lanes SF, et al. The association between asthma drugs and severe life-threatening attacks. Chest 1996;110:1446-51.

25 Bateman ED, Boushey HA, Bousquet J, et al. Can guideline-defined asthma control be achieved? The Gaining Optimal Asthma ControL study. Am J Respir Crit Care Med 2004; 170:836-44.

26 Bardin PG. Vaccination for asthma exacerbations. Intern Med J 2004;34:358-60.

\section{LUNG ALERT}

\section{Multidetector $\mathrm{CT}$ and the diagnosis of PE}

$\Delta$ Stein PD, Fowler SE, Goodman LR, et al. Multidetector computed tomography for acute pulmonary embolism. N Engl J Med 2006;22:2317-27

P revious studies have reported that the diagnostic sensitivity of single slice computed tomographic angiography (CTA) is approximately 70\%. However, the accuracy of multidetector CTA is uncertain. The PIOPED II study investigated the diagnostic accuracy of multidetector CTA in pulmonary embolism (PE) and whether the addition of peripheral venous phase imaging (CTV) improved diagnosis. Clinical assessment against a reference criterion was incorporated into this study.

824 patients were analysed, of whom 23\% had PE. The significance of the $17 \%$ missed diagnoses is probably not clinically relevant: previous outcome studies suggest that in these patients most thrombi do not need to be treated. The sensitivity of CTA in combination with CTV was $90 \%$.

The importance of a clinical risk score was highlighted in this study. An abnormal finding on multidetector CTA in combination with a high/intermediate clinical risk had a $93 \%$ positive predictive value (PPV). However, in those with a low clinical risk, the PPV of an abnormal CTA was only $58 \%$. A normal CTA in combination with a low/intermediate clinical risk of PE had a high negative predictive value (NPV) of approximately $93 \%$ whereas, in those with a high clinical risk, the NPV was only $60 \%$. Further investigation is therefore recommended when the clinical probability is inconsistent with the CTA result.

This study shows that the sensitivity of multidetector CTA for the diagnosis of PE is high. The importance of a clinical risk score was highlighted. CTA-CTV has an increased sensitivity over CTA alone. However, given the additional radiation, it may not improve the diagnostic yield enough to be routinely recommended.

J McLaughlin Medical SHO, Lagan Valley Hospital, Lisburn, UK; jacintamclaughlin@yahoo.co.uk 